\title{
AS DISPUTAS TERRITORIAIS ENTRE O AGRONEGÓCIO E O CAMPESINATO ${ }^{1}$
}

\author{
Leandro Reginaldo Maximino Lelis ${ }^{2}$ \\ Francisco José Avelino Júnior ${ }^{3}$
}

\section{RESUMO}

O campo brasileiro possui duas lógicas distintas de produção e organização: o agronegócio e o campesinato. Essa situação gera disputas territoriais entre essas duas lógicas. Assim, este artigo tem como objetivo analisar as disputas territoriais entre o agronegócio e o campesinato. A partir da leitura e análise do material bibliográfico selecionado e dos dados de fontes secundárias, notamos que o campesinato sofre com a violência praticada pelos capitalistas do agronegócio, porém continua lutando para entrar e permanecer na terra.

PALAVRAS-CHAVE: Disputas territoriais. Agronegócio. Campesinato.

\section{TERRITORIAL DISPUTES BETWEEN AGRIBUSINESS AND THE PEASANTRY}

\begin{abstract}
The Brazilian countryside has two different logics of production and organization: agribusiness and the peasantry. This situation generates territorial disputes between these two logics. Thus, this article aims to analyze the territorial disputes between agribusiness and the peasantry. From the reading and analysis of selected bibliography and secondary data sources, we note that the peasantry suffers from violence practiced by agribusiness capitalists, but still struggling to enter and remain in the land.
\end{abstract}

KEYWORDS: Territorial disputes. Agribusiness. Peasantry.

\section{DISPUTAS TERRITORIALES ENTRE AGRONEGOCIOS Y EL CAMPESINADO}

\footnotetext{
${ }^{1}$ Pesquisa de mestrado em desenvolvimento financiada pela Fundação de Apoio ao Desenvolvimento do Ensino, Ciência e Tecnologia do Estado de Mato Grosso do Sul (FUNDECT).

${ }^{2}$ Mestrando no Programa de Pós-Graduação em Geografia da Universidade Federal de Mato Grosso do Sul, campus de Três Lagoas. E-mail: sukko51@hotmail.com

${ }^{3}$ Docente do Programa de Pós-Graduação em Geografia da Universidade Federal de Mato Grosso do Sul, campus de Três Lagoas. E-mail: chinaufms@hotmail.com
} 


\section{RESUMEN}

En la actualidad, el campo brasileño tiene dos lógicas de producción y organización distinta: la agroindustria y el campesinado. Esta situación genera disputas territoriales entre estas dos lógicas. Este trabajo tiene como objetivo analizar las disputas territoriales entre la agroindustria y el campesinado. A partir de la lectura y análisis de bibliografía seleccionada y fuentes de datos secundarios, observamos que el campesinado sufre de la barbarie y la violencia practicada por los capitalistas agroindustriales, pero sigue luchando para entrar y permanecer en la tierra.

PALABRAS CLAVE: Las disputas territoriales. Agronegocios. Campesinado.

\section{INTRODUÇÃO}

Atualmente, o campo brasileiro é configurado pela existência de duas lógicas distintas de produção e organização: o agronegócio e o campesinato. Enquanto o agronegócio é produto do capital, o campesinato é considerado como um modo de produção tipicamente não capitalista. As divergências existentes entre o agronegócio e o campesinato resultam em disputas pelo território.

Neste contexto, este trabalho tem como objetivo analisar as disputas territoriais entre o agronegócio e o campesinato. Para atingir o objetivo proposto realizamos os seguintes procedimentos metodológicos: leitura e análise do material bibliográfico selecionado; e, coleta e sistematização dos dados de fontes secundárias. A leitura e análise do material bibliográfico ocorreu acerca dos seguintes temas: agronegócio; campesinato; e, disputas territoriais entre o agronegócio e o campesinato. A coleta dos dados de fontes secundárias ocorreu junto ao Instituto Brasileiro de Geografia e Estatística (IBGE) e à Comissão Pastoral da Terra (CPT). O recorte temporal desta pesquisa compreendeu o período entre os anos de 1990 e 2013.

\section{AS DIVERGÊNCIAS ENTRE O AGRONEGÓCIO E O CAMPESINATO}

Em virtude das transformações estruturais ocorridas, principalmente a partir da década de 1960, o campo brasileiro passou a se caracterizar por duas lógicas de produção e organização distintas: o agronegócio e o campesinato. Enquanto o agronegócio é baseado em grandes áreas de exploração e na prática da monocultura voltada à exportação, o campesinato é caracterizado por pequenas áreas de produção diversificada e pelo trabalho de base familiar (BEDUN, 2012). A 
respeito das divergências entre o agronegócio e o campesinato, Oliveira e Stedile (2005) destacam:

\begin{abstract}
O modo do agronegócio, [...] se baseia na grande propriedade, modernizada, quase sem trabalhadores, usando todo tipo de agrotóxico, monocultura, que não respeita o meio ambiente. $\mathrm{E}$, de outro lado, a agricultura camponesa, baseada em estabelecimentos agrícolas familiares, menores, que se dedicam à policultura (produzem vários produtos), que se dedicam à produção de alimentos, dão trabalho a milhares de pessoas, da família e de fora da família, que produzem e desenvolvem o mercado local e interno (OLIVEIRA; STEDILE, 2005, p. 32).
\end{abstract}

Cabe salientar que a palavra agronegócio é recente, surgiu na década de 1990, e foi criada com o intuito de apagar a imagem negativa que o latifúndio possuía. São palavras diferentes, mas que representam a mesma realidade. O agronegócio, assim como o latifúndio, segue os interesses da agricultura capitalista (FERNANDES, 2013). Segundo Fernandes (2013, p. 1), essa mudança de nome "é uma tentativa de ocultar o caráter concentrador, predador, expropriatório e excludente para relevar somente o caráter produtivista".

De acordo com Bedun (2012), a ideologia pautada no modelo agrícola desenvolvimentista e produtivista tem viabilizado a expansão desenfreada do capital no campo sob a forma do agronegócio. O Estado oferece políticas agrícolas, subsídios financeiros e vantagens creditícias que favorecem a disseminação do agronegócio. No entanto, o agronegócio provoca uma série de desdobramentos negativos. Para Fabrini (2008, p. 60): “[...] verifica-se que o agronegócio não possui sustentabilidade econômica e sobrevive à custa de intervenções políticas mantidas pelo Estado na forma de subsídios, perdão de dívidas, juros baixos, etc.".

Apesar dos benefícios amplamente divulgados por seus defensores, é necessário estarmos atentos às consequências negativas geradas pelo agronegócio, como enfatiza Fabrini (2010):

Em contraponto à concepção conservadora de defesa do agronegócio, alguns autores entendem que embora este setor tenha se tornado sinônimo de produtividade, ele é responsável por um conjunto de barbáries representadas pela miséria e pobreza, exclusão, superexploração do trabalho, violências, degradação ambiental, dentre outras (FABRINI, 2010, p. 63-64). 
Sobre os impactos socioambientais provocados pela expansão desenfreada do agronegócio no campo brasileiro, Canuto (2004) assinala:

\begin{abstract}
O agronegócio é devastador. Imensas áreas de florestas [...] estão sendo ilegalmente desmatadas, secando nascentes e mananciais, sugados pelo ralo das monoculturas, pastos de capim, carvoarias, mineradoras e madeireiras. Os agrotóxicos, despejados por aviões e tratores, estão contaminando solos, águas, ar e as plantações camponesas, causando doenças e mortes (CANUTO, 2004, p. 10).
\end{abstract}

Para Bedun (2012), a ideologia difundida pelo modelo agrícola baseado no modo capitalista de produção apresenta em seu discurso perspectivas ideais para o desenvolvimento do país. Assim:

[...] o agronegócio se apresenta como um modelo de produção promissor, rentável e próspero, responsável pela modernização da agricultura brasileira e assumindo, no campo, a função de gerar empregos, melhorar a qualidade de vida dos trabalhadores e promover o desenvolvimento econômico e social do Brasil (BEDUN, 2012, p. 70).

Entretanto, como é de amplo conhecimento, esse discurso não é real, pelo contrário, o agronegócio culmina na concentração de terra e de renda, pois atende exclusivamente os interesses do capital. Deste modo, para Bedun (2012), o agronegócio é pautado em uma lógica produtiva excludente, exploradora e concentradora.

Segundo Fernandes (2006), a ideologia disseminada, que coloca o agronegócio como sistema agrícola altamente produtivo e promovedor do desenvolvimento do país, faz com que as áreas ocupadas pelo agronegócio sejam protegidas da reforma agrária.

\begin{abstract}
A apologia ao agronegócio, realizada pela mídia, pelas empresas e pelo Estado, é uma forma de criar uma espécie de blindagem desse modelo, procurando invisibilizar sua conflitualidade. O agronegócio procura representar a imagem da produtividade, da geração de riquezas para o país. Desse modo, aparece como espaço produtivo por excelência, cuja supremacia não pode ser ameaçada pela ocupação da terra. Se o território do latifúndio pode ser desapropriado para a implantação de projetos de reforma agrária, o território do agronegócio apresenta-se como sagrado, que não pode ser violado (FERNANDES, 2006, p. 38, grifo do autor).
\end{abstract}

O discurso realizado pela mídia, por empresários, pelo Estado, entre outros, atribui ao agronegócio papel de destaque na economia brasileira, mascarando seus desdobramentos socioambientais negativos e seu real interesse. Esse discurso 
também foi capaz de mudar a visão a respeito dos grandes proprietários rurais, que passaram de latifundiários para empresários do agronegócio.

\begin{abstract}
O discurso positivo de segmentos sociais diversos (estudiosos, governantes, parlamentares e empresários, por exemplo) é de que o agronegócio possui grande importância para o País porque é responsável pela elevação da produção agrícola (alimentos), superávits da balança comercial, geração de emprego e renda, dentre outros benefícios. Vê-se com isso que de "vilões" que eram no passado, os grandes proprietários rurais do agronegócio, tornaram-se "heróis" da nação. Assim, as propriedades rurais latifundiárias, antes responsáveis pela miséria e pobreza porque não produziam, transformaram-se em verdadeiras empresas rurais, ou seja, imóveis altamente produtivos, explorados racionalmente e responsáveis por vários benefícios sociais e econômicos (FABRINI, 2010, p. 60).
\end{abstract}

Protegido pelo discurso do desenvolvimento, as políticas estatais têm beneficiado o território controlado pelo agronegócio, contribuindo para a expansão do capital e ampliação das desigualdades sociais no campo (BEDUN, 2012). No que se refere às políticas que beneficiam o agronegócio, Fabrini (2010) relata:

\begin{abstract}
Dentre as medidas políticas defendidas pelo agronegócio a serem tomadas pelo Estado está o veemente combate à ação dos movimentos sociais no campo, ocupações de terra e acampamentos realizados em todo o Brasil. Em passado recente, em favor do agronegócio, algumas medidas governamentais foram tomadas na esfera de ação do MDA (Ministério do Desenvolvimento Agrário) para conter as ocupações de terra. Este foi o caso da portaria 62/2001, fundamentada na Medida Provisória 2109-49 de 2000, do MDA, no governo de FHC, que determinou no seu artigo $1^{\circ}$ a proibição de vistoria e avaliação de imóveis ocupados pelos sem-terra no prazo de dois anos para fins de reforma agrária (FABRINI, 2010, p. 62-63).
\end{abstract}

Oliveira e Stedile (2005) apontam que o agronegócio tem se fortalecido cada vez mais no Brasil, tanto é que tem sido concebido como forma de organizar a agricultura. Tal situação evidencia o poder do agronegócio no campo brasileiro.

Agronegócio é qualquer operação comercial realizada com produtos agrícolas, mas no Brasil, virou a denominação de um modelo próprio de organizar a agricultura na forma de grandes fazendas modernas, com pouca mão-de-obra, com monocultura, que se especializam nas exportações (OLIVEIRA; STEDILE, 2005, p.5, grifo do autor).

De acordo com Fabrini (2010): "a partir do discurso dos setores dominantes da sociedade, o agronegócio se constitui no mais importante caminho para a agricultura brasileira, tornando-se paradigmático" (FABRINI, 2010, p. 60). Essa 
situação tem elevado a importância do agronegócio e desconsiderado as outras formas de produzir no campo, como é o caso do campesinato.

Oliveira (1996a) assinala que enquanto o agronegócio é pautado no lucro, o principal objetivo da produção camponesa é a sobrevivência dos membros da família. Sendo assim, a produção camponesa, primeiro, atende ao consumo direto familiar, como forma de subsistência imediata. O restante da produção, ou seja, o excedente, é comercializado sob a forma de mercadoria.

O agronegócio e o campesinato possuem lógicas de produção e organização distintas. Tal situação gera disputas pelo território. Destarte, o próximo item será dedicado à análise das disputas territoriais entre o agronegócio e o campesinato.

\section{AS DISPUTAS TERRITORIAIS ENTRE O AGRONEGÓCIO E O CAMPESINATO}

Para Oliveira (1996b), ao mesmo tempo em que o agronegócio expandiu-se pelo campo brasileiro, também houve "[...] aumento significativo dos movimentos sociais rurais, em luta pela terra ou por melhores condições de trabalho" (OLIVEIRA, 1996b, p. 523).

Apesar da luta no campo brasileiro por melhores condições ser antiga, Oliveira (1996b) afirma que o Movimento das Ligas Camponesas, entre as décadas de 1950 e 1960, foi a primeira forma mais organizada de movimento social rural. A respeito deste movimento, Oliveira (1996b) destaca:

\footnotetext{
Fundadas como sociedades beneficentes de defuntos, elas organizaram as lutas dos foreiros, moradores, arrendatários, pequenos proprietários e trabalhadores em geral da Zona da Mata nordestina, bem como a luta contra a expropriação e a exploração causadas pelo avanço dos latifúndios na região (OLIVEIRA, 1996b, p. 524).
}

De acordo com Fabrini (2010), por meio das lutas realizadas pelos movimentos sociais rurais, os camponeses resistem ao projeto de "desenvolvimento" para o campo brasileiro viabilizado pelo capital.

Segundo Bedun (2012), o desenvolvimento do capitalismo no campo tem proporcionado a territorialização do agronegócio e a desterritorialização do 
campesinato. Para a autora supracitada, a participação em movimentos sociais rurais é o principal meio para que os camponeses possam lutar pela terra.

Para Almeida (2006), a luta dos movimentos sociais rurais pela terra representa uma ruptura na territorialização e monopolização do território pelo capital. Conforme Fernandes (1999b), a luta dos movimentos sociais rurais:

[...] são ações de resistência frente à intensificação da concentração fundiária e contra a exploração, que marcam uma luta histórica na busca contínua da conquista da terra de trabalho, afim de obter condições dignas de vida e uma sociedade justa. São cinco séculos de latifúndio, de luta pela terra e de formação camponesa (FERNANDES, 1999b, p.15).

De acordo com Bedun (2012), a luta pela terra evidencia a resistência camponesa à expropriação, violência, exploração e sujeição provocadas pelo desenvolvimento do capitalismo no campo. Ainda para a autora: "as diversas manifestações e lutas desenvolvidas no campo pelos camponeses apontam para uma idéia de resistência e (re) criação contra a expropriação regida pela lógica capitalista" (BEDUN, 2012, p. 40).

As disputas territoriais entre os camponeses e o agronegócio, evidenciam a luta dos movimentos sociais pela terra e "[...] o enfrentamento do camponês a uma estrutura agrária calcada na concentração fundiária e monopolizada pelo capital" (BEDUN, 2012, p. 49-50).

A Tabela 1 evidencia a concentração fundiária no Brasil entre os anos 1995 e 2006. Nesta tabela, podemos notar que em 2006, por exemplo, os estabelecimentos agropecuários de até 100 hectares ocupavam apenas $21,4 \%$ da área total. Enquanto isso, os estabelecimentos acima de 100 hectares ocupavam 78,6\% da área total.

Tabela 01 - Área dos estabelecimentos agropecuários por grupo de área.

\begin{tabular}{lcccc}
\hline \multirow{2}{*}{$\begin{array}{l}\text { Grupos de área } \\
\text { (hectares) }\end{array}$} & \multicolumn{3}{c}{ Área dos estabelecimentos agropecuários (hectares) } \\
\cline { 2 - 5 } & \multicolumn{3}{c}{$\mathbf{1 9 9 5}$} & \multicolumn{2}{c}{$\mathbf{2 0 0 6}$} \\
Hectares & $\%$ & Hectares & $\%$ \\
Até $\mathbf{1 0}$ ha & 7.882 .194 & 2,2 & 7.798 .607 & 2,4 \\
De 10 a 100 ha & 62.693 .585 & 17,8 & 62.893 .091 & 19,0 \\
De 100 a 1.000 ha & 123.541 .517 & 34,9 & 112.696 .478 & 34,2 \\
Mais de 1.000 ha & 159.493 .949 & 45,1 & 146.553 .218 & 44,4 \\
Total & 353.611 .246 & 100 & 329.941 .393 & 100 \\
\hline
\end{tabular}


Fonte: Censo Agropecuário - IBGE (1995 e 2006).

A questão é que os estabelecimentos de até 100 hectares são a grande maioria do campo brasileiro (Tabela 2), mas controlam a menor parte das terras. Enquanto isso, os estabelecimentos com mais de 100 hectares são a minoria, porém concentram a maior parte das terras das terras brasileiras. Utilizando o ano de 2006 como exemplo, notamos que os estabelecimentos agropecuários de até 100 hectares representavam $90,4 \%$ do total, porém controlavam apenas $21,4 \%$ das terras. Já os estabelecimentos com área acima de 100 hectares, representavam apenas $9,6 \%$ do total de estabelecimentos, mas controlavam $78,6 \%$ da área.

Tabela 02 - Número de estabelecimentos agropecuários por grupos de área.

\begin{tabular}{lcccc}
\hline \multirow{2}{*}{$\begin{array}{l}\text { Grupos de área } \\
\text { (hectares) }\end{array}$} & \multicolumn{3}{c}{ Número de estabelecimentos agropecuários (unidades) } \\
\cline { 2 - 5 } & \multicolumn{2}{c}{$\mathbf{1 9 9 5}$} & \multicolumn{2}{c}{$\mathbf{2 0 0 6}$} \\
Quantidade & $\%$ & Quantidade & $\%$ \\
De $\mathbf{1 0}$ ha $\mathbf{1 0 0}$ ha & 2.402 .374 & 48,9 & 2.477 .151 & 50,3 \\
De $\mathbf{1 0 0} \mathbf{a} \mathbf{1 . 0 0 0}$ & 4.916 .487 & 39,9 & 1.971 .600 & 40,1 \\
ha & 469.964 & 9,9 & 424.288 & 8,6 \\
Mais de $\mathbf{1 . 0 0 0}$ ha & 49.358 & 1,3 & & \\
Total & 4.859 .865 & 100 & 4.920 .617 & 1,0 \\
\hline
\end{tabular}

Fonte: Censo Agropecuário - IBGE (1995 e 2006).

Conforme Bedun (2012), a história da estrutura agrária brasileira é caracterizada pela concentração de terras e, por consequência, "[...] pelos graves problemas sociais, econômicos e políticos presentes no campo" (BEDUN, 2012, p. 41). Ainda segundo Bedun (2012), as desigualdades sociais, a miséria, a pobreza e a insegurança alimentar são problemas intimamente ligados a concentração fundiária. Além disso, para a autora, a concentração fundiária se configura como obstáculo para os movimentos sociais rurais na luta pela terra de trabalho.

De modo amplo, a concentração fundiária moldada às bases do modelo produtivo do agronegócio, pautado na prática da monocultura agroexportadora e na superexploração do trabalho, configura um obstáculo para os movimentos sociais na luta pela terra decorrente da ausência de uma política de reforma agrária efetiva, capaz de romper com as injustiças sociais e com o modelo econômico centrado no capital monopolista (BEDUN, 2012, p. 51). 
Ao lutarem pela terra e pela reforma agrária, os movimentos sociais rurais "[...] têm se desenvolvido na contramão do discurso desenvolvimentista respaldado pelo agronegócio e apregoado pelo capital" (BEDUN, 2012, p. 59). Tal situação faz com que:

As elites concentradoras de terra respondem com a barbárie. Assim, o país vai prosseguindo no registro das estatísticas crescente sobre os conflitos e a violência no campo. A luta sem trégua e sem fronteiras que travam os camponeses e trabalhadores do campo por um pedaço de chão e contra as múltiplas formas de exploração de seu trabalho amplia-se por todo canto e lugar, multiplica-se como uma guerrilha civil sem reconhecimento. Essa realidade cruel é a face da barbárie que a modernidade gera no Brasil (OLIVEIRA, 2007, p. 151-152).

Assim, as divergências existentes entre a classe camponesa e a classe capitalista têm se desdobrado em violência no campo brasileiro, onde o capital persegue e aterroriza o trabalhador camponês. Para Bedun (2012):

[...] a relação entre camponeses e capitalistas sempre foi expressa por processos conflituosos, explicitados de um lado pelas formas capitalistas de desenvolvimento, engendradas sob a reprodução ampliada do capital e do poder, e do outro, a reprodução do trabalho familiar camponês fundamentada na tríade família, trabalho e terra (BEDUN, 2012, p. 41).

No que se refere à disputa territorial entre o agronegócio e o campesinato, Paulino e Almeida (2010, p. 58) constatam: "de um lado, a classe daqueles que usam a terra para extrair renda e lucro e produzir dominação política; do outro, a classe dos camponeses que da terra precisam para viver. O resultado tem sido um território em disputa!".

As disputas territoriais entre o campesinato e o agronegócio indicam lógicas divergentes de organização e produção no campo. Enquanto o camponês desenvolve suas atividades na propriedade familiar e produz de maneira diversificada para satisfazer suas necessidades básicas, o capitalista "[...] organizado na grande propriedade fundiária, baseada na monocultura exportadora, vive do lucro, fruto da exploração da força de trabalho" (BEDUN, 2012, p. 90-91).

Segundo Fernandes (2008, p. 280): "as propriedades camponesas e as capitalistas são territórios distintos, são totalidades diferenciadas, nas quais se 
produzem relações sociais diferentes, que promovem modelos divergentes de desenvolvimento".

A definição de Fernandes (2008) é clara ao apontar as diferenças entre os territórios do campesinato e os territórios capitalistas, nesse caso, representado pelo agronegócio.

\begin{abstract}
Os territórios do campesinato e os territórios do agronegócio são organizados de formas distintas, a partir de diferentes relações sociais. Um exemplo importante é que, enquanto o agronegócio organiza seu território para produção de mercadorias, o grupo de camponeses organiza seu território, primeiro, para sua existência, precisando desenvolver todas as dimensões da vida. Esta diferença se expressa na paisagem e pode ser observada nas distintas formas de organização dos dois territórios. A paisagem do território do agronegócio é homogênea, enquanto a paisagem do território camponês é heterogênea. A composição uniforme e geométrica da monocultura se caracteriza pela pouca presença de pessoas no território, porque sua área está ocupada por mercadoria, que predomina na paisagem. A mercadoria é a expressão do território do agronegócio. A diversidade dos elementos que compõem a paisagem do território camponês é caracterizada pela grande presença de pessoa no território, porque é neste e deste espaço que constroem sua existência, produzindo alimentos. Homens, mulheres, jovens, meninos e meninas, moradias, produção de mercadorias, culturas e infra-estrutura social, entre outros, são os componentes da paisagem dos territórios camponeses (FERNANDES, 2008, p. 285-289).
\end{abstract}

As relações de dominação e exploração utilizadas pelo capital sobre o trabalhador camponês dão origem aos conflitos territoriais entre o capital e o campesinato. Essas relações utilizadas pelo capital são estratégias para a manutenção de sua lógica e seus princípios. No entanto, os camponeses, não aceitando essas relações, lutam por sua autonomia política e econômica.

O capital gera a conflitualidade determinando a relação social dominante, tornando sempre subalterno o campesinato. Nessa condição, nasce o conflito, porque o capital, tentando manter sua lógica e seus princípios, enfrenta permanentemente os camponeses para continuar dominando-os. Por sua própria dignidade, os camponeses lutam continuamente pela autonomia política e econômica. A destruição e a recriação do campesinato pelo capital e a recriação do campesinato por si mesmo são processos diversos, com lógicas distintas, com valores diferentes (FERNANDES, 2006, p. 9, grifo do autor).

As disputas territoriais entre o capital e o campesinato são responsáveis pela ampliação da violência no campo brasileiro. Para Girardi e Fernandes (2009, p. 363): "[...] a violência tem sido utilizada pelo latifúndio e pelo agronegócio para expropriar 
e impedir a territorialização e a reterritorialização do campesinato". Destarte, a violência é utilizada pelos capitalistas para reprimir a luta camponesa pela terra. Nesse sentido, segundo Oliveira (2007, p. 135) a "[...] violência tem sido a principal característica da luta pela terra no Brasil".

No Brasil das últimas décadas, um grande número de conflitos, em geral sangrentos, tem acontecido no campo. Lideranças sindicais de trabalhadores, religiosos, advogados entre outros, têm sido cruelmente assassinados ao arrepio da lei. A justiça continua ser a única ausente do campo nos dias de hoje (OLIVEIRA, 1996a, p. 7).

A Tabela 3 apresenta os dados dos conflitos no Brasil entre os anos de 1990 e 2013. Entre os tipos de conflitos estão: conflitos por terra, água, trabalhistas, entre outros. Entre os anos de 1990 e 2013, o número de conflitos de terras oscilou. Entre 1990 e 2002, apenas no ano de 1998 foram registrados mais de 1.000 conflitos. Nesse ano, foram registrados 1.100 conflitos. No entanto, a partir de 2003 , todos os anos registraram mais de 1.000 conflitos, com destaque para o ano de 2005, que registrou 1.881 conflitos.

Tabela 03 - Número de conflitos no Brasil.

\begin{tabular}{cccccccc}
\hline Ano & $\begin{array}{c}\text { No de } \\
\text { conflitos }\end{array}$ & Ano & $\begin{array}{c}\text { No de } \\
\text { conflitos }\end{array}$ & Ano & $\begin{array}{c}\text { № de } \\
\text { conflitos }\end{array}$ & Ano & $\begin{array}{c}\text { № de } \\
\text { conflitos }\end{array}$ \\
\hline $\mathbf{1 9 9 0}$ & 448 & $\mathbf{1 9 9 6}$ & 750 & $\mathbf{2 0 0 2}$ & 925 & $\mathbf{2 0 0 8}$ & 1.170 \\
$\mathbf{1 9 9 1}$ & 453 & $\mathbf{1 9 9 7}$ & 736 & $\mathbf{2 0 0 3}$ & 1.690 & $\mathbf{2 0 0 9}$ & 1.184 \\
$\mathbf{1 9 9 2}$ & 433 & $\mathbf{1 9 9 8}$ & 1.100 & $\mathbf{2 0 0 4}$ & 1.801 & $\mathbf{2 0 1 0}$ & 1.186 \\
$\mathbf{1 9 9 3}$ & 545 & $\mathbf{1 9 9 9}$ & 983 & $\mathbf{2 0 0 5}$ & 1.881 & $\mathbf{2 0 1 1}$ & 1.363 \\
$\mathbf{1 9 9 4}$ & 485 & $\mathbf{2 0 0 0}$ & 660 & $\mathbf{2 0 0 6}$ & 1.657 & $\mathbf{2 0 1 2}$ & 1.364 \\
$\mathbf{1 9 9 5}$ & 554 & $\mathbf{2 0 0 1}$ & 880 & $\mathbf{2 0 0 7}$ & 1.538 & $\mathbf{2 0 1 3}$ & 1.266 \\
\hline
\end{tabular}

Fonte: Comissão Pastoral da Terra (1990 - 2013).

As disputas territoriais entre o agronegócio e o campesinato têm gerado conflitos marcados pela barbárie e violência. A Tabela 4 apresenta os dados referentes ao número de assassinatos ocorridos durante os conflitos no Brasil entre os anos de 1990 e 2013. Em 24 anos de conflitos ocorreram 974 assassinatos.

Tabela 04 - Número de assassinatos em conflitos no Brasil.

\begin{tabular}{lccccccc}
\hline Ano & Assassinatos & Ano & Assassinatos & Ano & Assassinatos & Ano & Assassinatos \\
\hline 1990 & 79 & 1996 & 54 & 2002 & 43 & 2008 & 28
\end{tabular}




\begin{tabular}{llllllll}
1991 & 54 & $\mathbf{1 9 9 7}$ & 30 & $\mathbf{2 0 0 3}$ & 73 & $\mathbf{2 0 0 9}$ & 26 \\
\hline $\mathbf{1 9 9 2}$ & 46 & $\mathbf{1 9 9 8}$ & 47 & $\mathbf{2 0 0 4}$ & 39 & $\mathbf{2 0 1 0}$ & 34 \\
\hline $\mathbf{1 9 9 3}$ & 52 & $\mathbf{1 9 9 9}$ & 27 & $\mathbf{2 0 0 5}$ & 38 & $\mathbf{2 0 1 1}$ & 29 \\
\hline $\mathbf{1 9 9 4}$ & 47 & $\mathbf{2 0 0 0}$ & 21 & $\mathbf{2 0 0 6}$ & 39 & $\mathbf{2 0 1 2}$ & 36 \\
\hline $\mathbf{1 9 9 5}$ & 41 & $\mathbf{2 0 0 1}$ & 29 & $\mathbf{2 0 0 7}$ & 28 & $\mathbf{2 0 1 3}$ & 34 \\
\hline
\end{tabular}

Fonte: Comissão Pastoral da Terra (1990 - 2013)

Para Bedun (2012), as tensões e a violência presentes nos conflitos agrários são evidencias das contradições existentes no desenvolvimento do capitalismo no campo. Conforme a autora, as contradições do capitalismo refletem "[...] o processo de uso e exploração do território. Neste contexto, o camponês é atingido pela violência da subordinação, exploração e expropriação, a partir da lógica desigual e contraditória do capital" (BEDUN, 2012, p. 61).

Ainda conforme Bedun (2012), os conflitos existentes no campo brasileiro não são amplamente divulgados, "[...] uma vez que a história do Brasil sempre esteve voltada para a classe dominante, controlada por latifundiários e capitalistas, e não em torno da luta e mobilização da classe de trabalhadores" (BEDUN, 2012, p. 60).

Segundo Thomaz Júnior (2009), a violência utilizada pelos capitalistas e pelo Estado contra os movimentos sociais é uma marca dos conflitos agrários brasileiros.

O expediente da violência e da truculência adotados pelas classes dominantes e pelo próprio Estado sustenta marcas indeléveis, tanto no que se refere aos assassinatos, quanto às perseguições e desaparecimentos de trabalhadores (posseiros, assalariados, pequenos produtores, etc), dirigentes sindicais e militantes dos diversos movimentos sociais envolvidos na luta pelo acesso à terra e resistência nela (THOMAZ JÚNIOR, 2009, p. 85).

Apesar da constante repressão e violência contra os trabalhadores camponeses, Thomaz Júnior (2009) aponta que essas barbáries não exterminaram o envolvimento e a luta dos trabalhadores pelo acesso à terra, por melhores condições no campo, dentre outros objetivos.

Nesse sentido, a repressão e a violência que engordam as fatídicas estatísticas das torturas, dos assassinatos, dos desaparecimentos de camponeses, lideranças sindicais $e$ trabalhadores rurais, bem como o comprometimento da maioria do Poder Judiciário com os imperativos do capital e do 
latifúndio, não fizeram desaparecer o envolvimento e a luta dos trabalhadores, sintonizados com o desejo do acesso a terra, à Reforma Agrária, às melhores condições de trabalho, ao cumprimento dos direitos trabalhistas, às denúncias de trabalho escravo etc. (THOMAZ JÚNIOR, 2009, p. 367).

Assim, mesmo com a violência utilizada pelos capitalistas do agronegócio, os camponeses seguem sua trajetória de luta para entrar na terra e nela permanecer, resistindo às perversidades impostas pelo desenvolvimento do capitalismo no campo.

\section{CONSIDERAÇÕES FINAIS}

O campo brasileiro tem sido palco de disputas territoriais entre lógicas distintas de reprodução. Enquanto a luta dos camponeses é para entrar e permanecer na terra de trabalho, a sociedade capitalista se articula para viabilizar a expansão do agronegócio, transformando a terra em mercadoria, como parte de sua estratégia de concentração de poder e renda.

A disputa territorial entre o agronegócio e o campesinato tem gerado conflitos. Os capitalistas do agronegócio utilizam a violência para reprimir a luta camponesa pela terra. Assassinatos aconteceram na luta pela terra, reforçando o caráter violento dos conflitos existentes no campo brasileiro.

Ao mesmo tempo que o agronegócio avança no campo brasileiro, o campesinato organiza-se entorno da luta pela terra, como parte de sua estratégia de resistência. Destarte, apesar da violência utilizada pelos capitalistas do agronegócio, o campesinato segue sua trajetória de luta para entrar e permanecer na terra.

\section{REFERÊNCIAS}

ALMEIDA, R. A. (Re)criação do campesinato, identidade e distinção: a luta pela terra e o habitus de classe. $1^{\underline{a}}$ ed. São Paulo: Editora UNESP, 2006.

BEDUN, M. R. Os desafios da agricultura familiar camponesa frente à territorialização do agronegócio: perspectivas para o município de Tupi Paulista e seu entorno regional. Dissertação (Mestrado em Geografia). 2012. 138 f. Universidade Federal de Mato Grosso do Sul, Três Lagoas, 2012.

CANUTO, A. Agronegócio: a modernização conservadora que gera exclusão pela produtividade. Revista NERA, Presidente Prudente, ano 7, n. 5, jul./dez. 2004, p. 1-12. Disponível em: <http://revista.fct.unesp.br/index.php/nera/article/viewFile/1466/1442>. Acesso em: 10 jan. 2015. 
CPT. Comissão Pastoral da Terra. Conflitos no campo Brasil (1990 a 2013). Disponível em: <http://www.cptnacional.org.br/index.php/component/jdownloads/viewcategory/43-conflitos-no-campobrasil-publicacao? Itemid=23>. Acesso em: 12 jan. 2015.

FABRINI, J. E. Latifúndio e agronegócio: semelhanças e diferenças no processo de acumulação de capital. Revista Pegada, Presidente Prudente, n.1, v.9, 2008, p.35-62.

. O campesinato frente à expansão do agronegócio e do agrocombustível. In: SAQUET, M. A.; SANTOS, R. A. (Orgs.). Geografia agrária, territórios e desenvolvimento. $1^{\underline{a}}$ ed. São Paulo: Expressão Popular, 2010, p.55- 88.

FERNANDES, B. M. Contribuição ao estudo do campesinato brasileiro: formação e territorialização do Movimento dos Trabalhadores Rurais Sem Terra MST (1979 - 1999). São Paulo, 1999b. Tese (Doutorado em Geografia Humana). Departamento de Geografia, Faculdade de Filosofia, Letras e Ciências Humanas da Universidade de São Paulo.

. Questão Agrária: conflitualidade e desenvolvimento territorial. Revista NERA, Presidente Prudente, 2006, p. 1-57. Disponível em:

<http://www2.fct.unesp.br/nera/artigodomes/Desenvolvimento_territorial.pdf>. Acesso em 20 jan.2012.

. Entrando nos territórios do Território. In: PAULINO, E. T.; FABRINI, J. E. (Orgs.).

Campesinato e territórios em disputa. $1^{\underline{a}}$ ed. São Paulo: Expressão Popular: UNESP. Programa de pós-graduação em geografia, 2008, p.273-301.

Agronegócio e reforma agrária. Disponível em: <http://www.gepec.ufscar.br/textos-

1/textos-educacao-do-campo/agronegocio-e-reforma-agraria/view>. Acesso em: 13 dez. 2013.

GIRARDI, E. P.; FERNANDES, B. M. Geografia das conflitualidades no campo brasileiro. In: FERNANDES, B. M.; MEDEIROS, L. S.; PAULILO, M. I. (Orgs.). Lutas camponesas contemporâneas: condições, dilemas e conquistas. Vol. 2. São Paulo: editora UNESP; Brasília,DF: Núcleo de estudos Agrários e Desenvolvimento Rural, 2009, p.339-366.

IBGE. Instituto Brasileiro de Geografia e Estatística. Censo Agropecuário (1995 e 2006). Disponível

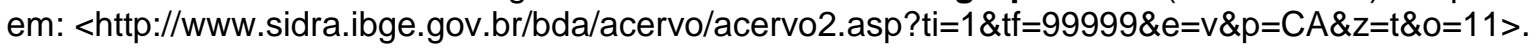
Acesso em: 15 jan. 2015.

OLIVEIRA, A. U. A agricultura camponesa no Brasil. 2ª ed. São Paulo: Contexto, 1996a.

. Agricultura Brasileira: Transformações Recentes. In: Jurandyr Luciano Sanches Ross (Org.), Geografia do Brasil. São Paulo: Edusp, 1996b, p. 467-534.

A geografia agrária e as transformações territoriais recentes no campo brasileiro. In: CARLOS, A. F. A. (Org.), Novos caminhos de Geografia. São Paulo: contexto, 2005, p. 63-110. Edições, 2007.

Modo de Produção Capitalista, Agricultura e Reforma Agrária. São Paulo: Labur

; STEDILE, J. P. A natureza do agronegócio no Brasil. Cartilha da Via Campesina. Brasília: Via Campesina Brasil, 2005.

PAULINO, E. T.; ALMEIDA, R. Terra e território: a questão camponesa no capitalismo. 1a. Ed. São Paulo: Expressão Popular, 2010.

THOMAZ JÚNIOR, A. Dinâmica Geográfica do Trabalho no Século XXI: Limites Explicativos, Autocrítica e Desafios Teóricos. Presidente Prudente, São Paulo: 2009. 